Case Report

\title{
Biliary cystadenoma a case report
}

\section{Amarjeet E. Tandur, Solaimuthu Rajagopal*, Rahul K. Mishra, Ajay H. Bhandarwar, Guru Bharadwaj, Bhushan Pathe}

Department of General Surgery, Grant Government Medical College \& Sir JJ group of Hospitals, Mumbai, Maharashtra, India

Received: 16 March 2021

Accepted: 16 April 2021

\section{* Correspondence:}

Dr. Solaimuthu Rajagopal,

E-mail: solaimuthuraja5@gmail.com

Copyright: (C) the author(s), publisher and licensee Medip Academy. This is an open-access article distributed under the terms of the Creative Commons Attribution Non-Commercial License, which permits unrestricted non-commercial use, distribution, and reproduction in any medium, provided the original work is properly cited.

\begin{abstract}
Biliary cystadenoma (BCA) is a rare cystic neoplasm of liver with malignant potential and female predominance, mostly asymptomatic that will lead to late identification. BCAs are mostly do not communicate with Biliary tract but communication was reported in some studies, BCA has higher rate of recurrence after incomplete removal so the standard management is complete resection or partial hepatectomy. We report a case of BCA in 72-year aged female with ECOG score 3. Computed tomography showed BCA involving segment II, III, IV and VIII of liver without any malignant features, which was treated with laparoscopic deroofing with omentopexy and no recurrence at 1 year follow up. We used indocyanine green-fluorescent image to look for biliary communication. This study aims to report that minimal accesses surgery with deroofing and omentopexy can be alternative treatment for BCA without any malignant features in a poor performance status and use of Indocyanine green-fluorescent image to avoid biliary injury and rule out communication.
\end{abstract}

Keywords: Biliary cystadenoma, Liver cyst, Indocyanine green-fluorescent imaging, Minimal access surgery

\section{INTRODUCTION}

Cystic diseases of liver occur in 5-10\% of the population. $^{1,2}$ Biliary cystadenoma (BCA) and cystadenocarcinoma (BCAC) are rare cystic neoplasms of the liver incidence $5 \%$ of all the cystic lesions of the liver. ${ }^{2}$ Origin may be intra hepatic or extra hepatic biliary ducts $(10 \%) .{ }^{3}$ Etiology is mainly unknown based on the mesenchymal stroma and the epithelium resembling endodermal (primitive hepatobiliary) cells that can be seen in BCT, Wheeler and Edmondson hypothesized that BCA arise from ectopic rests of embryonic bile ducts. $50 \%$ of BCAs found to have endocrine cells suggesting that the origin may be from intrahepatic peribiliary glands. BCAC is thought to originate from either denovo or acquired carcinogenesis in the pre-existing $\mathrm{BCA} .{ }^{1}$ Intrahepatic $\mathrm{BCA}$ are more common and predominantly occurs in Women (90\%) and usually asymptomatic.
BCAC is more evenly distributed among men and women. Based on the location of origin symptoms may differ. $^{1,4}$ These are first described by Heuter in 1887. BCA is believed to be premalignant with risk of malignant transformation up to $20-30 \% .^{5}$ BCAs are slow growing lesions with reported size in the range of 1.5-35 $\mathrm{cm}$. BCA has higher recurrence rate (nearly 90\%) after incomplete removal, all suspicious lesions must be completely removed. ${ }^{3,6}$ Deroofing with omentopexy has low recurrence rate. In 2009, Ishizawa et al reported the first application an indocyanine green-fluorescent image (ICG-FI) navigation system in the surgical treatment of liver tumour. ${ }^{7}$ On the finding during fluorescence cholangiography, it has been observed that ICG accumulates in primary tumor liver cells and around adenocarcinoma mass. ${ }^{8}$ Indocyanine green is a watersoluble, anionic, amphiphilic tricarbocyanine molecule, if illuminated with near infrared light $(700-900 \mathrm{~nm})$ emits 
fluorescence. ${ }^{9}$ Which after intravenous (IV) administration binds to high molecular weight plasma proteins and rapidly excreted in bile by active transport unmetabolized by hepatocytes. ${ }^{8,10}$ But in case of tumor because of deranged excretory function and surrounding hypoactive hepatocytes in case of non-hepatocellular tumors IGC get accumulated. ${ }^{8,11}$ Fluorescent light is largely attenuated by haemoglobin and water as it travels through biological tissues. Haemoglobin strongly attenuates all wavelengths less than $700 \mathrm{~nm}$. In visible and near-infrared light water is transparent but attenuates wavelengths over $900 \mathrm{~nm}$. There is a "window" (700-900 $\mathrm{nm}$ ) where tissue transparency is maximal. This is one of the reasons why ICG fluorescence can be detected in the near-infrared zone from as deep as $10 \mathrm{~mm}$ from the surface of tissues. ${ }^{8,10-12}$ Since the initial reports in 2009, more than 700 hepatectomy cases with the use of intraoperative FI for identification of liver tumors have been reported, with high sensitivity $(70 \%$ to $100 \%) .{ }^{12} \mathrm{We}$ present a case of unilocular biliary cystadenoma in 72year-old female where we used ICG-FI to rule out biliary communication.

\section{CASE REPORT}

We report here a 72-year-old female who present to outpatient department with pain in abdomen for 4 days and mass in abdomen since 3 to 4 months with history of loss appetite/weight. She was examined thoroughly fullness present at epigastrium on palpation the mass was ill-defined approximately $10 \times 10 \mathrm{~cm}$ in size and moves with respiration, on percussion dull note was present which was continuous with liver dullness. On ultrasonogram (USG) enlarged liver with anechoic cystic lesion of size $12 \times 12.8 \times 11.3 \mathrm{~cm}$ approximate volume 950 $\mathrm{cc}$ in left lobe of liver no e/o solid components/ internal septations/ calcifications/ vascularity. On contrast enhanced computed tomography (CECT)- which confirmed the USG finding of non-enhancing $11.6 \times 13.8 \times 12.8 \mathrm{~cm}$ lesion in segment II, III, IV and VIII of liver, with multiple similar small cystic lesions in right lobe of liver suggestive of BCA (Figure 1).

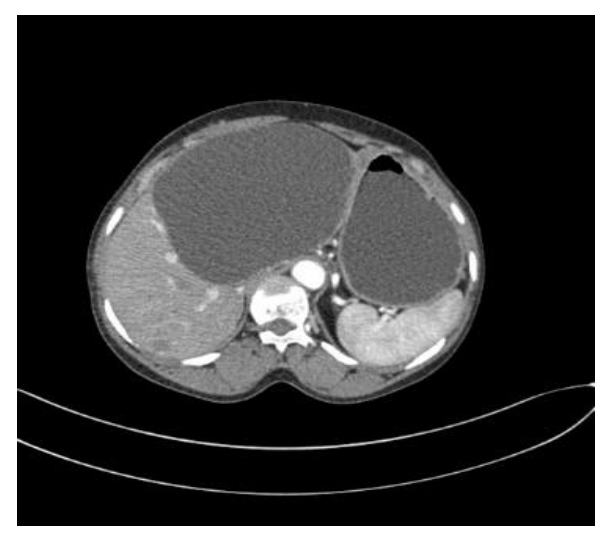

Figure 1: Contrast enhanced computed tomography (portal phase) abdomen showing unilocular cystic lesion in liver.
The patient's blood investigations are found to be in normal range. Decision was taken for deroofing of the cyst with omentopexy considering patients and considering patient's age and low life expectancy. Patient was given intravenous IGC 6 hours preoperatively and the BCA was found to be non-fluorescent with the surrounding fluorescent liver parenchyma (Figure 2) and with the help of ICG-FI biliary communication ruled out (Figure 3) as most of the BCA were and Laparoscopic deroofing of the cyst with omentopexy (Figure 4).

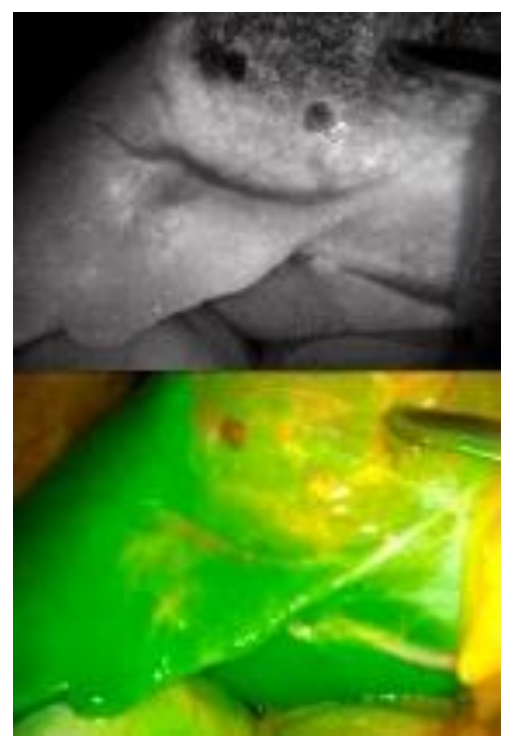

Figure 2: Intraoperative indocyanine greenfluorescent image showing surrounding fluorescent liver parenchyma.

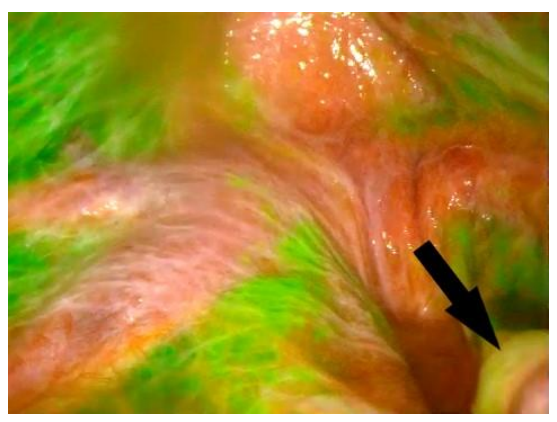

Figure 3: Indocyanine green-fluorescent image showing the intact bile duct in the wall of the cyst.

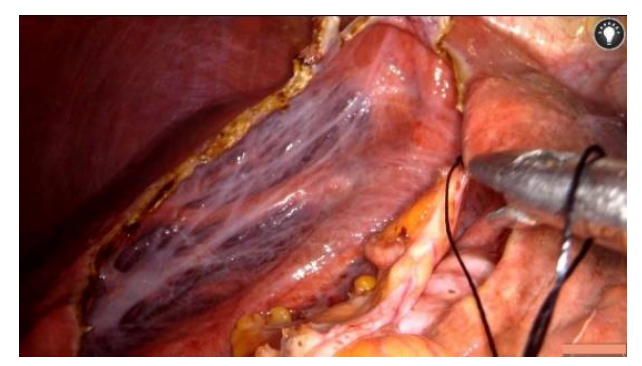

Figure 4: Omentopexy done with the cavity left. 
The deroofed specimen was sent for frozen section and reported to be have no malignant features and specimen sent for final histopathological examination (HPE). No intra operative or post operative complications occurred and the patient been discharged on post-operative day 4 after removal the drain which was kept at the site of the cyst output of which was decreased gradually without bile leak, fluid cytology report came as inconclusive since no viable cells present in the smear and histopathology of the cyst wall report suggestive of biliary cystadenoma with mesenchymal stroma. The patient was kept in a 6 monthly follow up with USG, $1^{\text {st }}$ follow up was done with USG Abdomen revealed no recurrence of the cystic lesion.

\section{DISCUSSION}

Biliary cystadenomas are commonly multilocular, in this patient it was a unilocular which was a very rare entity, usually occurring in middle aged female with 4:1 female: male ratio, and cystadenomas are known to increase in size during pregnancy and with oral contraceptive pills suggest its hormonal dependence. ${ }^{6,13,14}$ In this patient she was old age and had not taken any kind of hormonal supplements. BCA usually do not have communication with the biliary tree, but luminal communication was reported in some. In our case we used ICG dye to rule out biliary communication which was not found as in most of the BCA as in this patient also. In some cases, dysplastic mucinous epithelium itself may invade the bile ducts causing obstruction. This variant is intraductal papillary neoplasm with prominent cystic dilatation of the duct rather than a true biliary cystic neoplasm. CT and Magnetic resonance imaging (MRI) often fail to identify the narrow communication which is easily demonstratable during an intraoperative cholangiogram. ${ }^{14}$ Diagnosis of BCA can be made with USG and CT scan on ultrasound, the cystic nature of the lesion with multiple loculi, septations, and internal echoes, with papillary projections is typical, cyst wall enhancement in CECT scan can delineate further anatomic details the differential diagnosis are Simple liver cyst, Hydatid cyst, haemorrhagic cyst and Poly cystic disease of liver. ${ }^{3,14-17}$ An irregular wall thickening, mural nodule or presence of papillary projection indicate possibility of malignancy. ${ }^{3,16,18}$ A preoperative cyst fluid aspiration or core needle biopsy for diagnosis has been advocated in studies but diagnostic value is controversial and not accurate. Studies have suggested that cyst fluid CA 19-9 and CEA levels have positive predictive value in diagnosis of biliary cystadenoma and cystadenocarcinoma from other cystic lesion but normal value cannot rule out these. Moreover, both procedures have risk of dissemination of tumour cells. ${ }^{1-3,6,14,19} \mathrm{BCA}$ were historically treated with aspiration, marsupialization, internal Roux-en-Y anastomosis, sclerosis or partial resection all these associated with high complication rates including sepsis, continued growth and progression to malignancy and recurrence (90\%), which were lower in total ablative and resection procedure. ${ }^{6,13,14,17,18,20,21}$ So, in this patient we tried omentopexy additional to the deroofing of the cyst. Final diagnosis of the which is mainly done by HPE, BCA are usually of two types based on the stroma, one with the mesenchymal ovarian like stroma consist of compact spindle shaped cells usually immunoreactive with vimentin, alpha-smooth muscle actin, and musclespecific actin and less frequently with desmin, estrogen and progesterone receptors and support the epithelium seen exclusively in women. ${ }^{1,2,14,17}$ Which was reported to be BCA with mesenchymal stroma in this patient. Cystadenomas with mesenchymal stroma are considered premalignant with a good prognosis while those without are known to transform to malignancy more often with a poor prognosis. . $^{3,14,17}$

\section{CONCLUSION}

The diagnosis of BCA should be considered even in any unilocular cystic lesion of the liver, particularly in oldaged woman. The recommended treatment of choice for any suspected biliary cystadenoma is complete resection but for debilitated and old age patients deroofing with omentopexy can be considered as alternative treatment which was proven to be effective without any documented recurrence at 1-year, further trails can be done according the same and the use of IGC-FI in BCAs.

\section{ACKNOWLEDGEMENTS}

Authors would like to acknowledge the department of general surgery, Grant Government Medical College \& Sir J. J. group of Hospitals, Mumbai, India.

\section{Funding: No funding sources \\ Conflict of interest: None declared \\ Ethical approval: Not required}

\section{REFERENCES}

1. Soares KC, Arnaoutakis DJ, Kamel I, Anders R, Adams RB, Bauer TW, Pawlik TM. Cystic neoplasms of the liver: biliary cystadenoma and cystadenocarcinoma. J Am Coll Surg. 2014;218(1):119-28.

2. Brittingham C, Tuma F. Hepatic Cystadenoma. In: StatPearls. Treasure Island: StatPearls Publishing; 2021.

3. Peh KH, Eugene Chan BT. Biliary cystadenoma: A rare occurrence. Med J Malaysia. 2020;75(3):307-8.

4. Morris M, Anderson C, Drake L, Redfield S, Subramony C, Vanderlan W. Giant biliary cystadenoma. J Surg Case Rep. 2012 Sep;2012(9):15.

5. Jwa EK, Hwang S. Clinicopathological features and post-resection outcomes of biliary cystadenoma and cystadenocarcinoma of the liver. Ann Hepatobiliary Pancreat Surg. 2017;21(3):107-113.

6. Tholomier C, Wang Y, Aleynikova O, Vanounou T, Pelletier JS. Biliary mucinous cystic neoplasm 
mimicking a hydatid cyst: a case report and literature review. BMC Gastroenterol. 2019;19(1):103.

7. Zhang YM, Shi R, Hou JC, Liu ZR, Cui ZL, et al. Liver tumor boundaries identified intraoperatively using real-time indocyanine green fluorescence imaging. J Cancer Res Clin Oncol. 2017;143(1):51-8.

8. Rossi G, Tarasconi A, Baiocchi G, Angelis GL, Gaiani F, Mario F, Catena F, et al. Fluorescence guided surgery in liver tumors: applications and advantages. Acta Biomed. 2018;89(9-S):135-40.

9. Benedicenti S, Molfino S, Alfano MS, Molteni B, Porsio P, Portolani N, Baiocchi GL. IndocyanineGreen Fluorescence-GUIDED Liver Resection of Metastasis from Squamous Cell Carcinoma Invading the Biliary Tree. Case Rep Gastrointest Med. 2018;5849816.

10. Vlek SL, Dam DA, Rubinstein SM, Lange KESM, Schoonmade LJ, Tuynman JB, et al. Biliary tract visualization using near-infrared imaging with indocyanine green during laparoscopic cholecystectomy: results of a systematic review. Surg Endosc. 2017;31(7):2731-42.

11. Abo T, Nanashima A, Tobinaga S, Hidaka S, Taura $\mathrm{N}$, Takagi $\mathrm{K}$, et al. Usefulness of intraoperative diagnosis of hepatic tumors located at the liver surface and hepatic segmental visualization using indocyanine green-photodynamic eye imaging. Eur J Surg Oncol. 2015;41(2):257-64.

12. Nakaseko Y, Ishizawa T, Saiura A. Fluorescenceguided surgery for liver tumors. J Surg Oncol. 2018;118(2):324-31.

13. Joel JM, Jeyasingh SD, Kalyanaraman S. Biliary Cystadenoma: A Case Report. J Clin Diagn Res. 2016;10(2):19-20.

14. Ahanatha PS, Velayutham V, Perumal S, Ulagendra PS, Lakshmanan A, Ramaswami S, et al. Biliary cystadenomas: a case for complete resection. HPB Surg. 2012;501705.

15. Chen YW, Li CH, Liu Z, Dong JH, Zhang WZ, Jiang K. Surgical management of biliary cystadenoma and cystadenocarcinoma of the liver. Genet Mol Res. 2014;13(3):6383-90.

16. Billington PD, Prescott RJ, Lapsia S. Diagnosis of a biliary cystadenoma demonstrating communication with the biliary system by MRI using a hepatocytespecific contrast agent. $\mathrm{Br}$ J Radiol. 2012 Feb;85(1010):35-6.

17. Manouras A, Markogiannakis H, Lagoudianakis E, Katergiannakis V. Biliary cystadenoma with mesenchymal stroma: report of a case and review of the literature. World J Gastroenterol. 2006;12(37):6062-9.

18. Averbukh LD, Wu DC, Cho WC, Wu GY. Biliary Mucinous Cystadenoma: A Review of the Literature. J Clin Transl Hepatol. 2019;7(2):149-53.

19. Treska V, Ferda J, Daum O, Liska V, Skalicky T, Bruha J. Intrahepatic biliary cystadenoma-diagnosis and treatment options. Turk J Gastroenterol. 2016;27(3):252-6.

20. Thomas KT, Welch D, Trueblood A, Sulur P, Wise P, Gorden DL, et al. Effective treatment of biliary cystadenoma. Ann Surg. 2005;241(5):769-73.

21. Safari MT, Shahrokh S, Miri MB, Foroughi F, Sadeghi A. Biliary mucinous cystic neoplasm: a case report and review of the literature. Gastroenterol Hepatol Bed Bench. 2016;9(11):88-92.

Cite this article as: Tandur AE, Rajagopal SS, Mishra RK, Bhandarwar AH, Bharadwaj G, Pathe B. Biliary cystadenoma a case report. Int Surg J 2021;8:1621-4. 